\title{
Computational Studies on the Effects of Substituents on the Structure and Property of Zinc Dialkyldithiophosphates
}

\author{
Weiguo Xue, ${ }^{1}$ Xisheng Fu, ${ }^{1}$ Zhongping Tang, ${ }^{1}$ Gen Luo, ${ }^{2}$ Wenjie An, ${ }^{1}$ Tao Li, ${ }^{1}$ Yi Luo, ${ }^{1}$ Xuguang Zhou, ${ }^{1}$ \\ and Yi Luo ${ }^{2, *}$
}

\begin{abstract}
The substituent effect on the structure and property of zinc dialkyldithiophosphates (ZDDPs) have been investigated by DFT calculations. More than ten kinds of substituents including alkyl and aryl groups were chosen for assembling more than twenty ZDDPs. The structural features, thermal decomposition of ZDDP and the hydrolysis of alkaline tetranuclear zinc molecules with various alkyl and aryl substituents have been examined. It is found that the substituents have almost no effect on their central structures, but have significant effect on the thermal decomposition of alkyl- and arylsubstituted ZDDPs and their dimers. The calculations on the hydrolysis of tetranuclear ZDDPs suggest that the reaction free energies are affected by the substituents and the hydrolysis temperature. The radical species derived from ZDDP decomposition tends to be adsorbed on metal surface via multicoordination manner.
\end{abstract}

\section{Introduction}

Zinc dialkyldithiophosphates (ZDDPs) has been used as an additive for a long time in the formulation of lubricating oils by petrochemical industries. ${ }^{1,2}$ They were originally added to engine oils as antioxidants, as the same role of other antioxidants, such as cuprous dialkyldithiophosphate (CuDDP), organic molybdenum compounds (OMCs), and aromatic amines, etc. ${ }^{3-6}$ However, it was also found that it can act as a dispersant, a corrosion inhibitor and a detergent, especially as an anti-wear agent. $^{7-9}$ Due to the two most attractive performances (anti-wear and anti-oxidant functions) of ZDDP additives, they have been attracted much attention and have been widely investigated in the past decades. A good understanding of the substituent effect on the structure and property of ZDDP would be useful in the intelligent selection and design of alternative anti-wear additives. Although experimental studies are straightforward, they are often time-consuming, expensive, and wearisome. Alternatively, computational chemistry is a useful and powerful approach to obtain valuable information and predict some molecular parameters directly related to the corrosion inhibition behavior of the compounds. The structural features are the fundamental elements to understand the property of compounds. Previously, studies on structural characteristics of ZDDPs performed at several different levels of theory ${ }^{10-12}$ showed in good agreement with experimental data. An amount of experimental effort on the study of ZDDP anti-wear additives using various surface analytical techniques has shown that the ZDDP decomposition products rather than ZDDP themselves provide the wear protection. ${ }^{13-15}$ To 
have more information about the behavior of ZDDP anti-wear additives, some studies have been performed at finite temperature through $a b$ initio molecular dynamics simulations and static quantum chemical calculations. ${ }^{10,11,16-19}$ These studies gave deep understanding of experimental observations and provided some key insights into the basic chemical behavior of these additives. However, most of these theoretical studies focused on model ZDDP molecules with small alkyl substituents (i.e. $\mathrm{R}=$ $\mathrm{H}, \mathrm{Me},{ }^{i} \mathrm{Pr}$ etc). Very little is known regarding the effect of larger substituents on the structure and property of ZDDPs, such as $C_{8}, C_{10}$, $\mathrm{C}_{12}$ alkyl groups, although such information is crucial for the development of ZDDP additives. In the present study, eleven kinds of substituents including alkyl and aryl groups were chosen for assembling more than twenty zinc compounds. Most of these substituents are often used in the experiment. DFT calculations have been performed on the structural features of these assembled ZDDP monomers. The thermal decomposition of these ZDDP monomers and their dimers and the hydrolysis of tetranuclear zinc alkaline molecules with a variety of alkyl and aryl substituents have been investigated. The information obtained from these calculations could add better understanding to the substituent effect on the structure and property of zinc dialkyldithiophosphates and might provide valuable information on the development of lubricating oil additives.

\section{Computational Details}

All calculations were performed with Gaussian 09 software package. ${ }^{20}$ All of the stationary points were optimized without any geometrical symmetry restriction. Geometrical optimizations were performed using B3LYP functional. ${ }^{21,22}$ Vibrational frequencies were also calculated at the same level of theory in order to confirm each optimized structure as a minimum $\left(N_{\text {imag }}=0\right)$ and obtain the thermal correction to the free energy. As for ZDDP monomers and dimers, the $6-31 \mathrm{G}(\mathrm{d})$ basis set was used for all nonmetallic atoms and the relativistic effective core potentials $\operatorname{Lan} L 2 D Z^{23,24}$ was considered for $\mathrm{Zn}$ atoms. This basis set was called BSI. The bond dissociation energy (BDE), where contains the basis set superposition error (BSSE) correction, was calculated at the same level as that for geometrical optimization. The electronic energies were used for analysis of BDE in this study. In the calculations of tetranuclear dialkyldithiophosphate zinc complex, due to the large molecular size of the complexes (i.e. the largest molecule $\mathbf{1 9}$ has 479 atoms), the geometrical optimizations and vibrational frequencies were performed at the B3LYP/BSII level. In BSII, the 6-31G(d) basis set was used for $O, P$, and $S$ atoms and $3-21 G(d)$ was used for $\mathrm{C}$ and $\mathrm{H}$ atoms of the outermost alkyl group, and LanL2DZ was used for $\mathrm{Zn}$ atom. For consideration of aqueous solvation effects during the hydrolysis reaction, the CPCM model ${ }^{25,26}$ was utilized to perform single-point

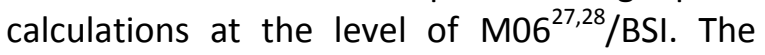
reaction free energies in aqueous solution were obtained from such single-point calculations, and the gas-phase Gibbs free energy corrections were included. In the calculations of metal surface adsorption part, $\mathrm{Fe}_{5}$ cluster, which has the structural features of $\mathrm{Fe}(100)$ surface, was used as a metal surface model to investigate the interaction energy of ZDDP with metal surface as well as the adsorption behavior of the radical species. Because of the complexity and time consuming of the calculation, a cluster of iron consisting of five atoms $(1,4)$ with spin multiplicity of five was chosen for the calculation, as adopted in the previous work. ${ }^{29}$ In this part, the LanL1MB pseudopotential basis set $^{30}$ was used for Fe atoms and the 6-31G(d) (for $\mathrm{C}, \mathrm{H}, \mathrm{O}$, and P)/LanL2DZ (for $\mathrm{Zn}$ ) basis sets were used for the atoms of ZDDP molecule. To consider the adsorption of active elements $(O$ and $\mathrm{S}$ ) at metal cluster, the scan energy curves for $\mathrm{Fe} \cdots \mathrm{O}$ and $\mathrm{Fe} \cdots \mathrm{S}$ distances between ZDDP and $\mathrm{Fe}_{5}$ cluster were carried out and the minimum energy point was chosen as the minima structure for obtaining the adsorption energy.

\section{Results and Discussion}




\section{Structure and thermal decomposition investigation of ZDDP monomers}

The structural aspects of the monomers are of significant interest in the study of ZDDPs and have been the focus of several previous theoretical and experimental investigations. ${ }^{10-}$ 12,31,32 The structure of ZDDP monomer has been well established and its general structure is shown in Figure 1 . The two dialkyldithiophosphate (DDP) ligands chelate $\mathrm{Zn}$ atom by the two $S$ atoms in each DDP ligand and the orientation of the two DDP ligands is perpendicular.

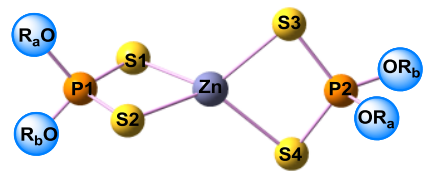

Figure 1. General structure of ZDDP monomer.

$$
\begin{array}{ll}
\mathrm{R}_{1}={ }^{i} \mathrm{C}_{3} \mathrm{H}_{7} \text { (isopropyl) } & \mathrm{R}_{7}= \\
\mathrm{R}_{2}={ }^{n} \mathrm{C}_{4} \mathrm{H}_{9} \text { (n-butyl) } & \\
\mathrm{R}_{3}={ }^{i} \mathrm{C}_{5} \mathrm{H}_{11} \text { (2-methyl-butyl) } & \mathrm{R}_{8}= \\
\mathrm{R}_{4}={ }^{n} \mathrm{C}_{8} \mathrm{H}_{17} \text { (n-octyl) } & \\
\mathrm{R}_{4}={ }^{i} \mathrm{C}_{8} \mathrm{H}_{17} \text { (5-ethyl-hexyl) } & \mathrm{R}_{9}= \\
\mathrm{R}_{5}={ }^{i} \mathrm{C}_{10} \mathrm{H}_{21} \text { (2-methyl-nonyl) } & \\
\mathrm{R}_{6}={ }^{n} \mathrm{C}_{12} \mathrm{H}_{23} \text { (n-dodecyl) } & \mathrm{R}_{10}=
\end{array}
$$
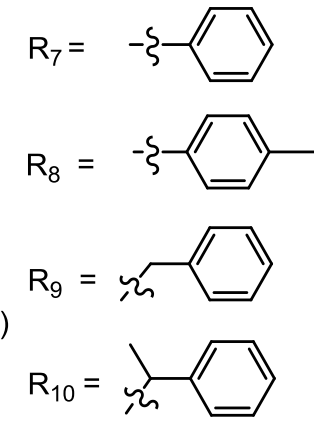

Chart 1. Substituents used in this study.

To have a better understanding of the effect of $\mathrm{R}$ groups on the structural aspects, eleven alkyl and aryl groups (see Chart 1), which often appears in the experimentally used ZDDP, were chosen for investigating the structures. Eleven ZDDP monomers (compounds 1-11) comprised by one or two kinds of $\mathrm{R}$ groups were optimized by DFT calculations. In the case of large alkyl substitutes, only the most stable conformer with zigzag alkyl chain was considered. The important bond lengths of such monomers are collected in Table 1 . The data in this table shows that the P-S bond lengths are 2.02-2.04 $\AA$ and the $\mathrm{Zn}-\mathrm{S}$ bond lengths are $2.46-2.48 \AA$ for all complexes. The difference in the bond lengths of ZDDP monomers with various substituents is less than $0.03 \AA$, suggesting that the $R$ groups have very little effect on the geometric parameters of ZDDP core structures.

It is generally accepted that ZDDPs undergo decomposition under engine operation conditions, such as high temperature and high pressure. The further reaction of these decomposition products could lead to the formation of zinc poly(thio)phosophate film. ${ }^{33-38}$ A molecular-level examination of thermostability of ZDDP monomers with various of substituents may provide useful information on the behavior of their thermal decomposition. In this part, we evaluated the possible decomposition pathways by bond dissociation energy of the key bonds of ZDDP molecules. As shown in Scheme 1, several possible dissociation manners were considered by DFT calculations. Paths $\mathbf{a}$ and $\mathbf{b}$ are the dissociation of $\mathrm{Zn}-\mathrm{S}$ bond via homolysis and heterolysis manners, respectively. The homolysis of $\mathrm{Zn}-\mathrm{S}$ bond results in $\mathrm{DDP}^{\circ}$ and $\mathrm{Zn}$ $\mathrm{DDP}^{\circ}$ radical fragments. The homolysis of $\mathrm{P}-\mathrm{S}$ bond could form (RO) ${ }_{2} \mathrm{PS}^{\circ}$ and (DDP)ZnS ${ }^{\circ}$ (Path c). The other two kinds of homolysis of $\mathrm{P}-\mathrm{O}$ (Paths $\mathbf{d}$ and $\mathbf{e}$ ) and $\mathrm{C}-\mathrm{O}$ (Paths $\mathbf{f}$ and $\mathbf{g}$ ) bonds lead to the loss of alkoxy/aryloxy and alkyl/aryl radicals, respectively. All these possible dissociation pathways were calculated and the results were listed in Table 2.

As shown in Table 2, for all substituted ZDDP monomers, the bond dissociation energies (BDEs) of heterolysis of $\mathrm{Zn}-\mathrm{S}$ bonds are as high as $165-174 \mathrm{kcal} / \mathrm{mol}$, which are significantly higher than that for their corresponding homolysis manners (ca $75-76 \mathrm{kcal} / \mathrm{mol}$ ). Therefore, the homolysis manner of ZDDP monomers is more likely to occur. The BDEs of homolysis of $\mathrm{P}-\mathrm{S}$ bonds are $82-85 \mathrm{kcal} / \mathrm{mol}$ for all cases (Path $\mathbf{c}$ in Table 2). The homolysis of $\mathrm{P}-$ $\mathrm{O}$ and $\mathrm{C}-\mathrm{O}$ bonds via Paths $\mathbf{d}$ to $\mathbf{f}$ have similar BDE values (79-87 kcal $/ \mathrm{mol}$,) when both $R_{a}$ and $R_{b}$ are alkyl groups (compounds $\mathbf{1 - 8}$ in Table 2 ). The result suggests that the homolysis of $\mathrm{P}-\mathrm{O}$ and $\mathrm{C}-\mathrm{O}$ bonds are competitive and the homolysis of $\mathrm{Zn}-\mathrm{S}$ bonds, forming DPP radical, is the main decomposition manner when both $R_{a}$ and $R_{b}$ are alkyl groups. However, the aryl 


\begin{tabular}{|c|c|c|c|c|c|c|c|c|c|}
\hline \multirow{2}{*}{ Compounds } & \multirow{2}{*}{ Substituents } & \multicolumn{8}{|c|}{ Bond length $(\AA \dot{A})$} \\
\hline & & $\mathrm{P} 1-\mathrm{S} 1$ & $\mathrm{P} 1-\mathrm{S} 2$ & P2-S3 & $\mathrm{P} 2-\mathrm{S} 4$ & $\mathrm{Zn}-\mathrm{S} 1$ & $\mathrm{Zn}-\mathrm{S} 2$ & $\mathrm{Zn}-\mathrm{S} 3$ & $\mathrm{Zn}-\mathrm{S} 4$ \\
\hline 1 & $R_{a}=R 1, R_{b}=R 2$ & 2.029 & 2.031 & 2.041 & 2.028 & 2.474 & 2.471 & 2.469 & 2.462 \\
\hline 2 & $\mathrm{R}_{\mathrm{a}}=\mathrm{R} 2, \mathrm{R}_{\mathrm{b}}=\mathrm{R} 4$ & 2.027 & 2.028 & 2.040 & 2.025 & 2.472 & 2.476 & 2.469 & 2.465 \\
\hline 3 & $R_{a}=R 2, R_{b}=R 3$ & 2.027 & 2.027 & 2.039 & 2.026 & 2.471 & 2.476 & 2.469 & 2.463 \\
\hline 4 & $\mathrm{R}_{\mathrm{a}}=\mathrm{R} 1, \mathrm{R}_{\mathrm{b}}=\mathrm{R} 4$ & 2.029 & 2.029 & 2.041 & 2.027 & 2.471 & 2.474 & 2.469 & 2.463 \\
\hline 5 & $\mathrm{R}_{\mathrm{a}}=\mathrm{R}_{\mathrm{b}}=\mathrm{R} 5$ & 2.027 & 2.027 & 2.040 & 2.026 & 2.472 & 2.475 & 2.469 & 2.464 \\
\hline 6 & $\mathrm{R}_{\mathrm{a}}=\mathrm{R}_{\mathrm{b}}=\mathrm{R} 6$ & 2.027 & 2.027 & 2.040 & 2.027 & 2.473 & 2.475 & 2.470 & 2.462 \\
\hline 7 & $\mathrm{R}_{\mathrm{a}}=\mathrm{R} 1, \mathrm{R}_{\mathrm{b}}=\mathrm{R} 9$ & 2.029 & 2.030 & 2.042 & 2.027 & 2.473 & 2.474 & 2.467 & 2.463 \\
\hline 8 & $R_{a}=R 1, R_{b}=R 10$ & 2.032 & 2.033 & 2.040 & 2.028 & 2.468 & 2.475 & 2.470 & 2.463 \\
\hline 9 & $\mathrm{R}_{\mathrm{a}}=\mathrm{R}_{\mathrm{b}}=\mathrm{R} 7$ & 2.019 & 2.020 & 2.028 & 2.021 & 2.479 & 2.474 & 2.470 & 2.466 \\
\hline 10 & $\mathrm{R}_{\mathrm{a}}=\mathrm{R} 1, \mathrm{R}_{\mathrm{b}}=\mathrm{R} 7$ & 2.027 & 2.025 & 2.035 & 2.026 & 2.479 & 2.470 & 2.469 & 2.462 \\
\hline 11 & $\mathrm{R}_{\mathrm{a}}=\mathrm{R} 1, \mathrm{R}_{\mathrm{b}}=\mathrm{R} 8$ & 2.027 & 2.025 & 2.036 & 2.027 & 2.478 & 2.470 & 2.469 & 2.462 \\
\hline
\end{tabular}

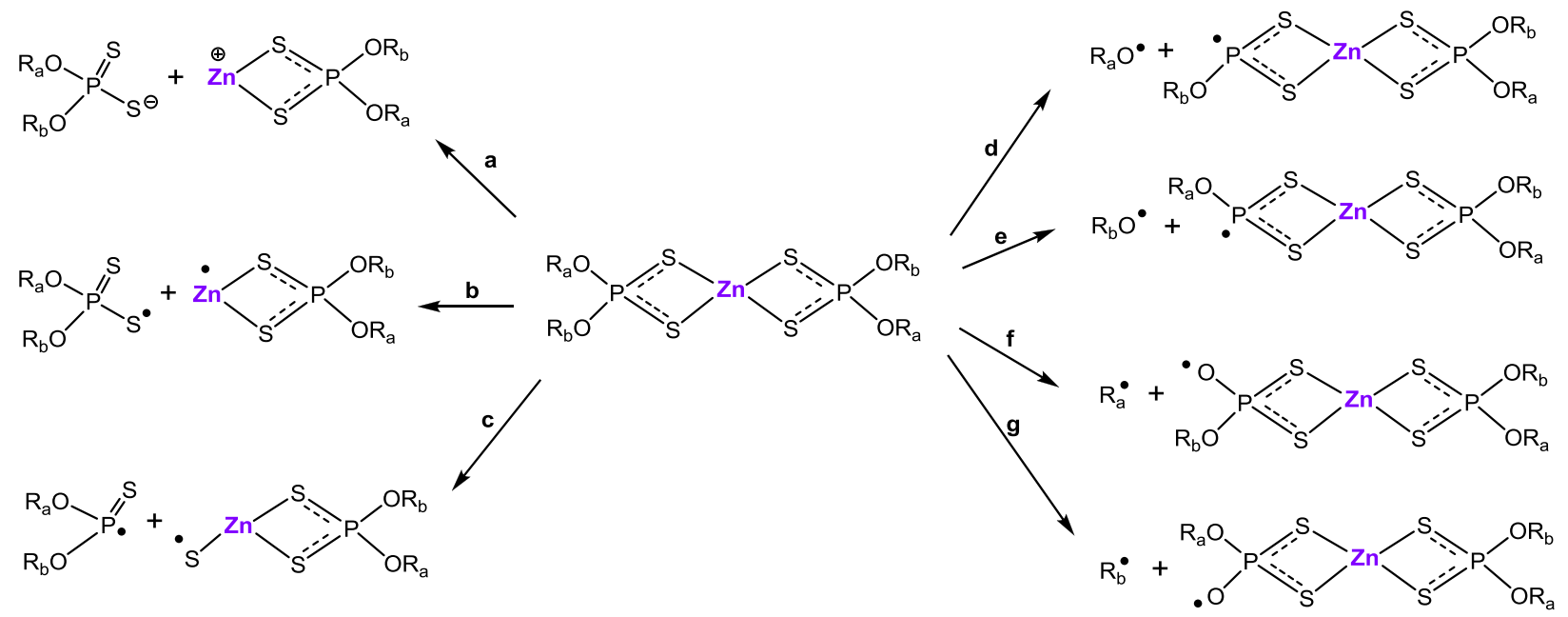

Scheme 1. Possible Dissociation Manners for the ZDDP Monomers.

substituents would significantly reduce the BDEs of the homolysis of $\mathrm{P}-\mathrm{O}$ bonds and increase the BDEs of $\mathrm{C}-\mathrm{O}$ bonds. The $\mathrm{BDE}$ calculations of compounds 9-11 show that the BDEs of the homolysis of $\mathrm{P}-\mathrm{O}$ bonds (Path e) are 64-66 kcal/ $\mathrm{mol}$, which are even lower than that of $\mathrm{Zn}-\mathrm{S}$ bond homolysis. The BDEs of the homolysis of $\mathrm{C}-\mathrm{O}$ bonds (Path $\mathbf{g}$ ) are $\mathrm{Ca} 92$ $\mathrm{kcal} / \mathrm{mol}$. Therefore, the loss of aryloxy radicals is favored over the loss of aryl radicals for aryl substituted ZDDP monomers investigated in this study. The homolysis of $\mathrm{P}-\mathrm{O}$ bonds, forming $\mathrm{RO}^{\circ}$ radical, is the main decomposition manner when aryl substituents are present in the ZDDP molecules, which is different from that of the homolysis of $\mathrm{Zn}-\mathrm{S}$ bonds for the full-alkyl substituted ZDDPs. It is noted that, in the resulting DDP anion or radical, the charge or unpaired electron delocalized on both $\mathrm{S}$ atoms (see Figure S1 in SI). 
Table 2. Bond Dissociation Energy $(\mathrm{BDE}, \mathrm{kcal} / \mathrm{mol})$ of the Main Chemical Bonds of the ZDDP Monomers in Different Dissociation Manners. ${ }^{[a]}$

\begin{tabular}{|ccccccccc|}
\hline \multirow{2}{*}{ Compounds } & Substituents & \multicolumn{7}{c}{ BDE in different dissociation manners } \\
\cline { 3 - 8 } & & $\mathbf{a}$ & $\mathbf{b}$ & $\mathbf{C}$ & $\mathbf{d}$ & $\mathbf{e}$ & $\mathbf{f}$ & $\mathbf{g}$ \\
\hline $\mathbf{1}$ & $\mathrm{R}_{\mathrm{a}}=\mathrm{R} 1, \mathrm{R}_{\mathrm{b}}=\mathrm{R} 2$ & 169.9 & 76.1 & 84.7 & 82.3 & 83.1 & 84.5 & 86.5 \\
$\mathbf{2}$ & $\mathrm{R}_{\mathrm{a}}=\mathrm{R} 2, \mathrm{R}_{\mathrm{b}}=\mathrm{R} 4$ & 169.8 & 75.9 & 84.3 & 83.7 & 83.6 & 86.6 & 86.2 \\
$\mathbf{3}$ & $\mathrm{R}_{\mathrm{a}}=\mathrm{R} 2, \mathrm{R}_{\mathrm{b}}=\mathrm{R} 3$ & 169.8 & 76.0 & 84.6 & 83.6 & 83.7 & 86.5 & 86.2 \\
$\mathbf{4}$ & $\mathrm{R}_{\mathrm{a}}=\mathrm{R} 1, \mathrm{R}_{\mathrm{b}}=\mathrm{R} 4$ & 169.6 & 75.9 & 84.3 & 83.5 & 83.3 & 84.6 & 86.3 \\
$\mathbf{5}$ & $\mathrm{R}_{\mathrm{a}}=\mathrm{R}_{\mathrm{b}}=\mathrm{R} 5$ & 169.2 & 75.9 & 84.6 & 83.6 & 83.6 & 86.4 & 86.4 \\
$\mathbf{6}$ & $\mathrm{R}_{\mathrm{a}}=\mathrm{R}_{\mathrm{b}}=\mathrm{R} 6$ & 169.2 & 75.9 & 84.6 & 83.6 & 83.6 & 86.5 & 86.5 \\
$\mathbf{7}$ & $\mathrm{R}_{\mathrm{a}}=\mathrm{R} 1, \mathrm{R}_{\mathrm{b}}=\mathrm{R} 9$ & 167.0 & 76.1 & 84.2 & 82.6 & 82.9 & 84.9 & 78.9 \\
$\mathbf{8}$ & $\mathrm{R}_{\mathrm{a}}=\mathrm{R} 1, \mathrm{R}_{\mathrm{b}}=\mathrm{R} 10$ & 167.4 & 76.0 & 84.0 & 81.4 & 80.8 & 84.7 & 80.8 \\
$\mathbf{9}$ & $\mathrm{R}_{\mathrm{a}}=\mathrm{R}_{\mathrm{b}}=\mathrm{R} 7$ & 165.2 & 75.0 & 82.5 & 65.8 & 65.8 & 92.6 & 92.6 \\
$\mathbf{1 0}$ & $\mathrm{R}_{\mathrm{a}}=\mathrm{R} 1, \mathrm{R}_{\mathrm{b}}=\mathrm{R} 7$ & 173.8 & 75.8 & 84.5 & 82.1 & 65.2 & 84.6 & 92.9 \\
$\mathbf{1 1}$ & $\mathrm{R}_{\mathrm{a}}=\mathrm{R} 1, \mathrm{R}_{\mathrm{b}}=\mathrm{R} 8$ & 167.1 & 75.7 & 84.4 & 82.0 & 64.2 & 84.4 & 93.0 \\
\hline [a] Dissociation manners defined in scheme 1. & & & & & & \\
\hline
\end{tabular}
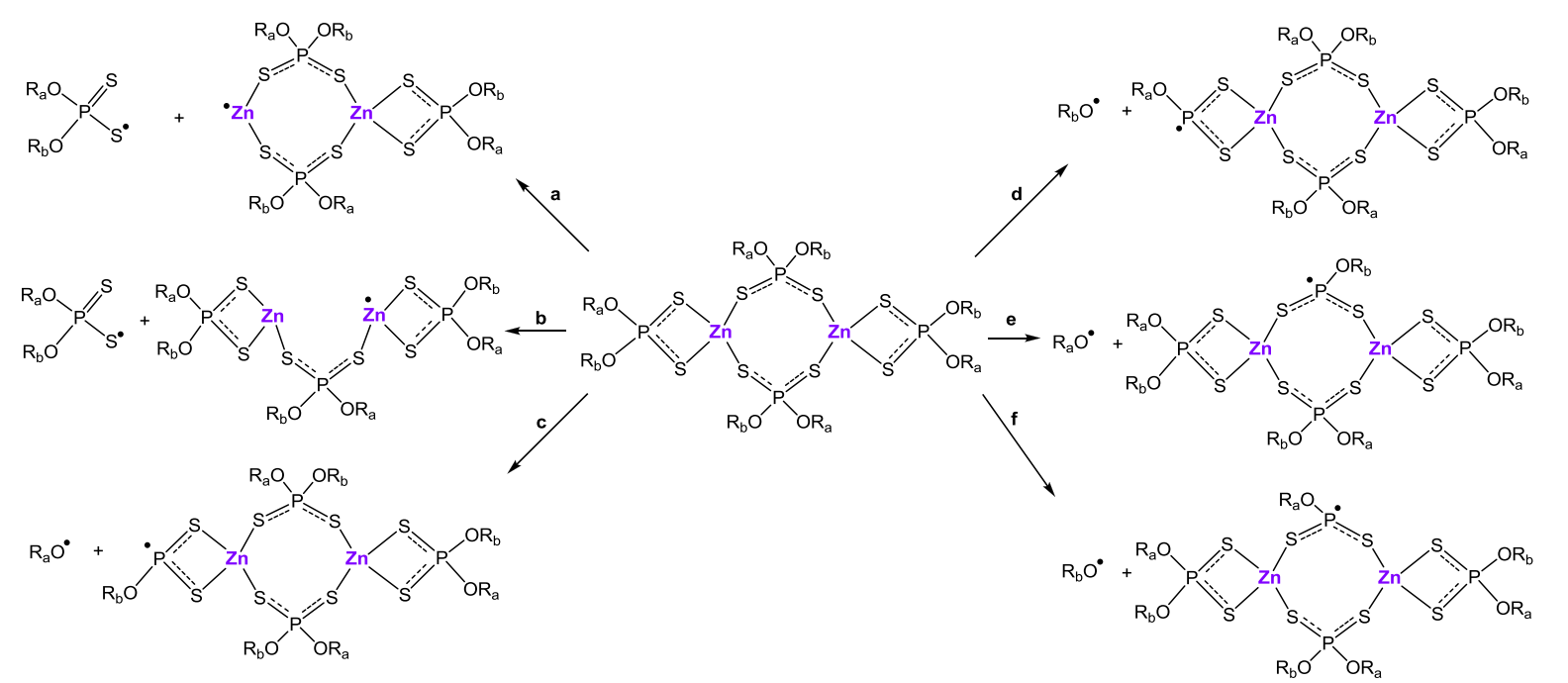

Scheme 2. Possible Dissociation Processes for the ZDDP Dimers.

To evaluate the effect of basis set, a larger basis set $6-311+G(d, p)$ for nonmetallic atoms and LanL2DZ for $\mathrm{Zn}$ atom were used for calculation of several smaller ZDDP monomers. The results show that the usage of larger basis set doesn't alter the results derived from smaller basis set (see Tables S1 and S2 in supporting information). Therefore, the reported results at the level of B3LYP/BSI could be reliable.

\section{Thermal decomposition investigation of ZDDP dimers}

It is well known that ZDDP molecules exist in solution not only as monomers but also as dimers or even higher order oligomers. ${ }^{39-41}$ Based on information obtained through experimental ${ }^{42-44}$ and theoretical investigations, ${ }^{32,45}$ it is known that the ZDDP dimer $\mathrm{Zn}_{2}\left[\mathrm{PS}_{2}(\mathrm{OR})_{2}\right]_{4}$ possesses two bridging DDP ligands connecting the two $\mathrm{Zn}$ atoms and two terminal DDP ligands chelating each $\mathrm{Zn}$ atom (Scheme 2). Although the structures of ZDDP dimers are well established, there is very limited information on their thermal decomposition behavior. In the above section, we have carefully examined the thermal decomposition behavior of ZDDP monomers, and it is found that the homolysis of $\mathrm{Zn}-\mathrm{S}$ and $\mathrm{P}-\mathrm{O}$ bonds are the main decomposition manner 
of ZDDPs with different kinds of substituents. Based on this result, only the homolysis of $\mathrm{Zn}-\mathrm{S}$ and $\mathrm{P}-\mathrm{O}$ bonds, including the bridging and terminal DDP ligands, were considered in ZDDP dimer cases. As shown in Scheme 2, the Paths a and $\mathbf{b}$ are the homolysis of $\mathrm{Zn}-\mathrm{S}$ bonds of bridging and terminal DDP ligands, respectively. The Paths $\mathbf{c}$ and $\mathbf{d}$ are the homolysis of $\mathrm{P}-\mathrm{O}$ bonds of terminal DDP ligands and the Paths $\mathbf{e}$ and $f$ are the homolysis of $\mathrm{P}-\mathrm{O}$ bonds of bridging DDP ligands.

The data showed in Table 3 indicates that the BDE values for the dissociation of terminal DDP ligands (ca $75 \mathrm{kcal} / \mathrm{mol}$, Path a) are very similar to that for ZDDP monomers (Path $\mathbf{b}$ in Table 2). By contrast, the BDE values for the dissociation of bridging DDP ligands are ca $96 \mathrm{kcal} / \mathrm{mol}$, which is ca $20 \mathrm{kcal} / \mathrm{mol}$ higher than that for the terminal cases. This means that the bridging DDP ligands are more stable than terminal ones. For all the homolysis of $\mathrm{P}-\mathrm{O}$ bonds in ZDDP dimers, the BDEs are $82-85 \mathrm{kcal} / \mathrm{mol}$, which are similar to that in ZDDP monomers. The values suggest that the dissociation of terminal DDP ligands is the main decomposition manner when both $R_{a}$ and $R_{b}$ are alkyl groups (compound $\mathbf{1 2}$ in Table 3). As expected, the aryl substituents significantly reduce the stability of $\mathrm{P}-\mathrm{O}$ bonds, as suggested by the BDE values (65$67 \mathrm{kcal} / \mathrm{mol}$, compounds $\mathbf{1 3 - 1 5}$ in Table 3). The loss of aryloxy radicals (ca 65-67 kcal $/ \mathrm{mol}$ ) is favored over the loss of aryl radicals (83-85 $\mathrm{kcal} / \mathrm{mol}$ ) for aryl substituted ZDDP dimers. Similar to ZDDP monomers, the of $\mathrm{P}-\mathrm{O}$ bond homolysis leading to $\mathrm{RO}^{\circ}$ radical is the main decomposition manner when aryl substituents are present in the ZDDP molecules.

\section{The hydrolysis reaction of tetranuclear dialkyldithiophosphate zinc complexes}

It is known that tetranuclear alkaline ZDDPs with $\left[\mathrm{Zn}_{4}\left(\mu_{4}-\mathrm{O}\right)\right]$ core structure could be formed by a spontaneous precipitation from the corresponding initial liquid binuclear complexes as a result of oxidation by atmospheric oxygen. ${ }^{46}$ The structures of tetranuclear $\mathrm{Zn}$ (II) dialkyldithiophosphate complexes, $\left[\mathrm{Zn}_{4} \mathrm{X}\left\{\mathrm{S}_{2} \mathrm{P}(\mathrm{OR})_{2}\right\}_{6}\right](\mathrm{X}=\mathrm{O}, \mathrm{S})$, have been studied.
And, the result showed that these tetranuclear complexes possess six bridging ligands and a central sulfur or oxygen atom coordinates to four $\mathrm{Zn}$ atoms. ${ }^{47-49} \mathrm{O}^{\prime}$ Brien and co-workers reported that the $X$-ray single crystal structures of a series of tetranuclear $\mathrm{Zn}$ complexes, viz., $\left[\mathrm{Zn}_{4}\left(\mu_{4}-\mathrm{O}\right)\left(\mathrm{O}_{2} \mathrm{CNEt}_{2}\right)_{6}\right], \quad\left[\mathrm{Zn}_{4}\left(\mu_{4}-\mathrm{O}\right)\left(\mathrm{S}_{2} \mathrm{PEt}_{2}\right)_{6}\right]$, and $\left[\mathrm{Zn}_{4}\left(\mu_{4}-\mathrm{O}\right)\left(\mathrm{S}_{2} \mathrm{CNEt}_{2}\right)_{6}\right] .{ }^{50}$ Rheingold et al isolated the complex $\mathrm{Zn}_{4}\left(\mu_{4}-\mathrm{O}\right)\left[\mathrm{O}_{2} \mathrm{P}\left(\mathrm{O}^{t} \mathrm{Bu}\right)_{2}\right]_{6}{ }^{51}$ and provided the structural information of solid tetranuclear Zn complexes. Experimentally, the hydrolysis reaction of tetranuclear dialkyldithiophosphate $\mathrm{Zn}$ complexes could occur to yield two molecules of dinuclear $\mathrm{Zn}$ complexes: $\mathrm{Zn}_{4}\left(\mu_{4}-\mathrm{O}\right)\left[\mathrm{S}_{2} \mathrm{P}\left(\mathrm{OR}_{\mathrm{a}}\right)\left(\mathrm{OR}_{\mathrm{b}}\right)\right]_{6}+\mathrm{H}_{2} \mathrm{O} \rightarrow 2$ $\mathrm{Zn}_{2}\left(\mu_{2}-\mathrm{OH}\right)\left[\mathrm{S}_{2} \mathrm{P}\left(\mathrm{OR}_{\mathrm{a}}\right)\left(\mathrm{OR}_{\mathrm{b}}\right)\right]_{3}+\Delta G$ (reaction free energy). However, there is little available information about the effect of R (alkyl and aryl) groups of the DDP ligands. In this study, the hydrolysis reaction of six tetranuclear dialkyldithiophosphate $\mathrm{Zn}$ complexes with different $\mathrm{R}$ groups was computed under the temperature range of $40-120^{\circ} \mathrm{C}$. The computed reaction free energies are illustrated in Table 4 and Figure 2.

As shown in Table 4, when the $\mathrm{R}$ groups are isopropyl (C3) and $n$-butyl (C4), the hydrolysis reaction $\left(\Delta G_{1}\right)$ of compound $\mathbf{1 6}$ is endothermic by $12.3 \mathrm{kcal} / \mathrm{mol}$ at the $40{ }^{\circ} \mathrm{C}$. When the $\mathrm{R}$ groups are large alkyl groups, i.e. isopentyl (C6), isodecyl (C8), and n-dodecyl (C12), the hydrolysis free energies $\left(\Delta G_{2}\right.$ to $\left.\Delta G_{4}\right)$ of compounds 17-19 are lower than that of compound $\mathbf{1 6}$ with small substituent groups $\left(\Delta G_{1}\right)$ at the same temperature. It is noteworthy that the aryl groups could increase the hydrolysis stability of tetranuclear alkaline ZDDPs. The reaction free energies $\left(\Delta G_{5}\right.$ and $\left.\Delta G_{6}\right)$ of aryl substituted alkaline ZDDPs $\mathbf{2 0}$ and $\mathbf{2 1}$ are obviously higher than that of full-alkyl substituted complexes (16-19). Figure 2 clearly illustrates that the reaction free energies of all tetranuclear alkaline ZDDPs decrease with the increase of hydrolysis temperature. Obviously, the hydrolysis reaction of $\mathbf{1 8}$ becomes an exothermic reaction when the temperature increases to $120{ }^{\circ} \mathrm{C}$. As for compound 19, the 


\begin{tabular}{|c|c|c|c|c|c|c|c|}
\hline \multirow{2}{*}{ Compounds } & \multirow{2}{*}{ Substituents } & \multicolumn{6}{|c|}{ BDE in different dissociation manners } \\
\hline & & a & b & c & d & e & $\mathbf{f}$ \\
\hline 12 & $R_{a}=R 2, R_{b}=R 1$ & 75.7 & 96.5 & 83.7 & 84.6 & 83.2 & 82.9 \\
\hline 13 & $\mathrm{R}_{\mathrm{a}}=\mathrm{R} 7, \mathrm{R}_{\mathrm{b}}=\mathrm{R} 1$ & 75.2 & 96.6 & 66.6 & 83.9 & 65.5 & 83.0 \\
\hline 14 & $R_{a}=R 8, R_{b}=R 1$ & 75.1 & 96.4 & 65.4 & 83.9 & 64.4 & 82.9 \\
\hline 15 & $R_{a}=R_{b}=R 7$ & 75.7 & 96.6 & 66.3 & 66.3 & 65.3 & 65.3 \\
\hline
\end{tabular}

\begin{tabular}{|c|c|c|c|c|c|c|c|c|c|c|c|}
\hline \multirow{2}{*}{$\begin{array}{c}\text { Compou } \\
\text { nds }\end{array}$} & \multirow{2}{*}{ Substituents } & \multirow{2}{*}{$\Delta G$} & \multicolumn{9}{|c|}{ Temperature $\left({ }^{\circ} \mathrm{C}\right)$} \\
\hline & & & 40 & 50 & 60 & 70 & 80 & 90 & 100 & 110 & 120 \\
\hline 16 & $R_{a}=R 1, R_{b}=R 2$ & $\Delta G_{1}$ & 12.3 & 11.8 & 11.4 & 10.9 & 10.5 & 10.0 & 9.6 & 9.1 & 8.7 \\
\hline 17 & $\mathrm{R}_{\mathrm{a}}=\mathrm{R}_{\mathrm{b}}=\mathrm{R} 4^{\prime}$ & $\Delta G_{2}$ & 10.6 & 10.2 & 9.8 & 9.4 & 9.0 & 8.6 & 8.2 & 7.8 & 7.3 \\
\hline 18 & $\mathrm{R}_{\mathrm{a}}=\mathrm{R}_{\mathrm{b}}=\mathrm{R} 5$ & $\Delta G_{3}$ & 5.8 & 5.0 & 4.3 & 3.6 & 2.8 & 2.1 & 1.3 & 0.6 & -0.1 \\
\hline 19 & $\mathrm{R}_{\mathrm{a}}=\mathrm{R}_{\mathrm{b}}=\mathrm{R} 6$ & $\Delta G_{4}$ & 2.3 & 1.7 & 1.0 & 0.4 & -0.3 & -1.0 & -1.6 & -2.3 & -2.9 \\
\hline 20 & $\mathrm{R}_{\mathrm{a}}=\mathrm{R} 1, \mathrm{R}_{\mathrm{b}}=\mathrm{R} 7$ & $\Delta G_{5}$ & 14.7 & 14.3 & 14.0 & 13.7 & 13.4 & 13.0 & 12.7 & 12.4 & 12.1 \\
\hline 21 & $R_{a}=R 1, R_{b}=R 8$ & $\Delta G_{6}$ & 17.4 & 17.1 & 16.8 & 16.6 & 16.3 & 16.1 & 15.8 & 15.6 & 15.3 \\
\hline
\end{tabular}

hydrolysis reaction is exothermic when the temperature reaches $80{ }^{\circ} \mathrm{C}$. Based on these results, we can conclude that large alkyl groups and high temperature would promote the hydrolysis reaction of tetranuclear dialkyldithiophosphate $\mathrm{Zn}$ complexes and aryl groups could restrain the hydrolysis reaction to occur in comparison with full-alkyl substituted cases.

\section{The adsorption behavior of ZDDP monomer on the metal surface}

The ZDDP molecules containing hetero-atoms $(\mathrm{P}, \mathrm{S}, \mathrm{O})$ could adsorb on metallic surfaces under engine conditions or similar conditions in the laboratory. Iron surface is one of the most common metal surfaces and $\mathrm{Fe}_{5}$ cluster having the features of $\mathrm{Fe}(100)$ surface (Figure 3 ) was considered for investigating the interaction between ZDDP and metal surface. ${ }^{29,52}$ To investigate the adsorption capacity of different hetero-atoms of ZDDP molecules, the model ZDDP molecule $\left[\left(\mathrm{Me}_{2} \mathrm{O}\right) \mathrm{PS}_{2}\right]_{2} \mathrm{Zn}$ was used for the calculation. Since $P$ atoms is surrounded by $O$ and $\mathrm{S}$ atoms and therefore is difficult to directly interact with metal surface before ZDDP decays. Therefore, only the adsorption of active element $\mathrm{O}$ and $\mathrm{S}$ over $\mathrm{Fe}_{5}$ cluster were considered. The rigid scan of $\mathrm{O} \cdots \mathrm{Fe}$ and $\mathrm{S} \cdots \mathrm{Fe}$ distances between ZDDP and $\mathrm{Fe}_{5}$ cluster were performed. In such calculations, the $\mathrm{Fe}_{5}$ cluster was fixed and the specified $\mathrm{O}$ or $\mathrm{S}$ atom of ZDDP was placed at the above of top-Fe atom of $\mathrm{Fe}_{5}$ cluster in the initial model.

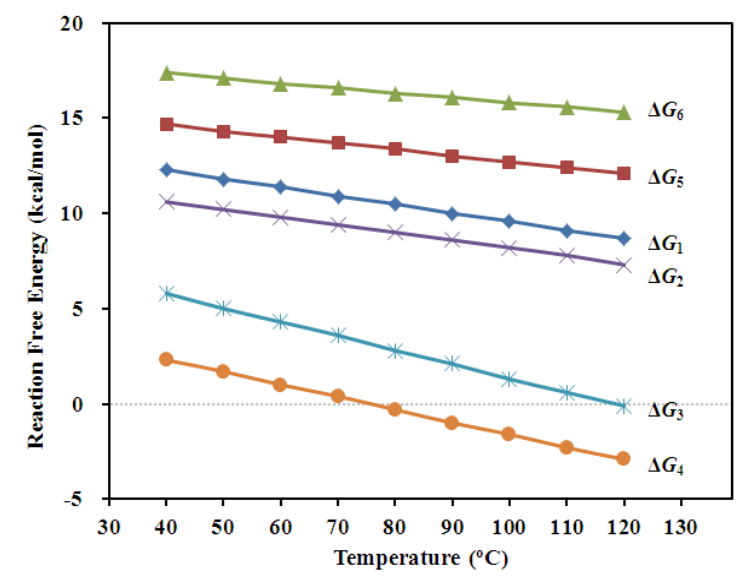

Figure 2. The reaction free energy $(\mathrm{kcal} / \mathrm{mol})$ for the hydrolysis of tetranuclear $\mathrm{Zn}$ complexes under different temperatures. 


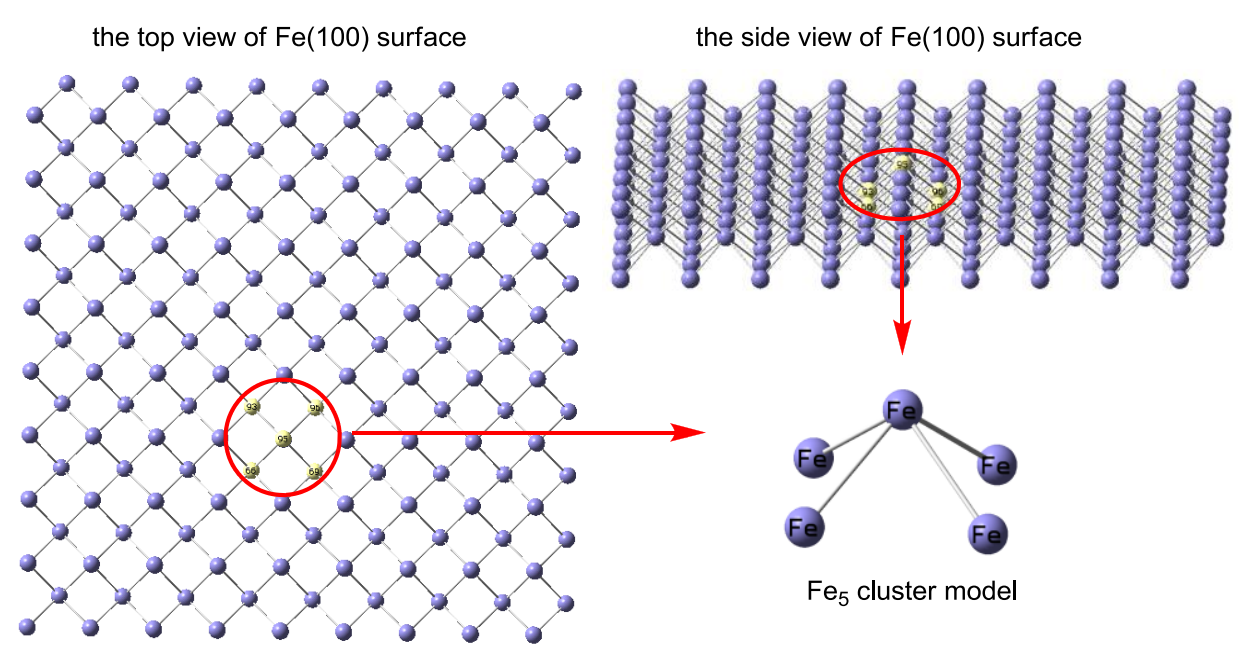

Figure 3. Fe (100) surface and its model structure ( $\mathrm{Fe}_{5}$ cluster).

As shown in Figure 4, the minimum energy point in the scan curve was chosen as the minima structure for obtaining the adsorption energy. The adsorption energy $\left(E_{\text {int }}\right)$ of $\mathrm{O}$ (or S) atom was estimated by the energy difference between the energy of the lowest point in the scan curve and the energy sum of isolated ZDDP and $\mathrm{Fe}_{5}$ cluster.

As illustrated in Figure $4 \mathrm{a}$, the $\mathrm{O}$ atom of ZDDP gradually gets close to the Fe atom of $\mathrm{Fe}_{5}$ cluster from $2.65 \AA$ to $2.05 \AA$ (step size $=0.02 \AA$ ). The corresponding energy curve shows that the energy reduces as the $\mathrm{O} \cdots \mathrm{Fe}$ distance reduces from $2.65 \AA$ to $2.45 \AA$ and the energy increases as the $\mathrm{O} \cdots \mathrm{Fe}$ distance further reduces. Therefore, the minimum energy point $(\mathrm{O} \cdots \mathrm{Fe}$ distance of $2.45 \AA$ ) in scan curve could be used to estimate the adsorption energy of $O$ atom. The adsorption energy of $\mathrm{O}$ atom is calculated to be $19.3 \mathrm{kcal} / \mathrm{mol}$.

As for the scan of the S...Fe distance, the $S$ atom of ZDDP gradually gets close to the $\mathrm{Fe}$ atom of $\mathrm{Fe}_{5}$ cluster from $2.80 \AA$ to $2.20 \AA$ (step size $=0.02 \AA)$. Similar to the scan of $0 \cdots \mathrm{Fe}$ distance, the energy reduces as the S...Fe distance reduces from $2.80 \AA$ to $2.44 \AA$ and the energy increases as the $\mathrm{S}$...Fe distance further reduces (Figure $4 \mathrm{~b}$ ). It is obvious that the energy curve for $\mathrm{S}$ atom adsorption is steeper in comparison with that of $\mathrm{O}$ atom adsorption. The adsorption energy of $\mathrm{S}$ atom was calculated to be $97.1 \mathrm{kcal} / \mathrm{mol}$, which is significantly larger
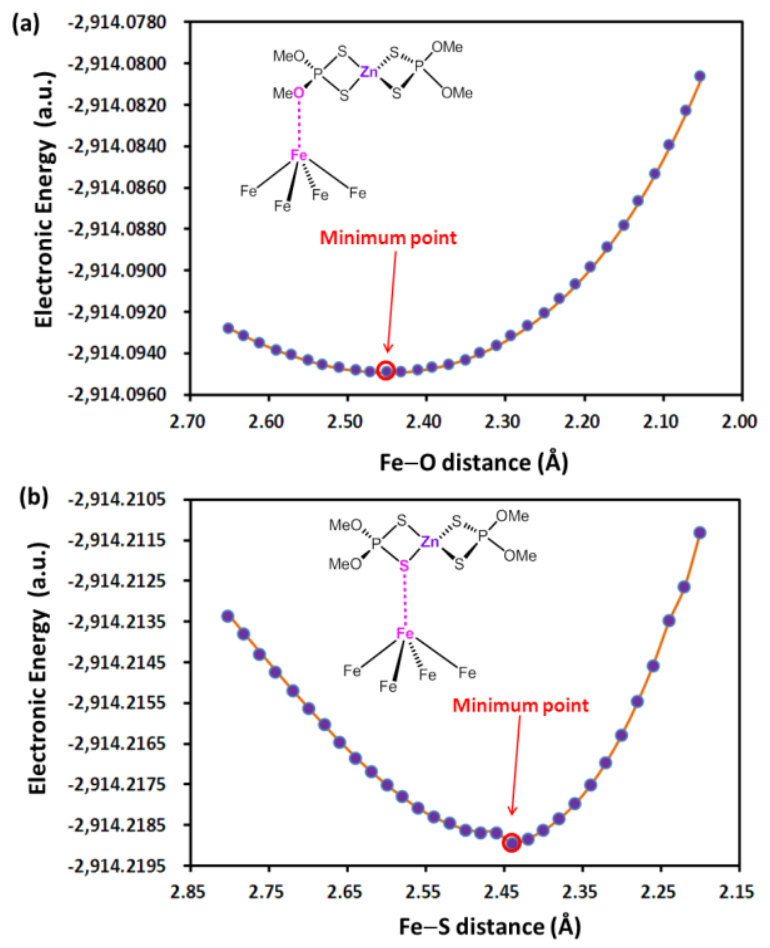

Figure 4. The scan energy curve for $\mathrm{Fe} \cdots \mathrm{O}$ (a) and $\mathrm{Fe} \cdots \mathrm{S}$ distance (b) between ZDDP and $\mathrm{Fe}_{5}$ cluster.

than that of $\mathrm{O}$ atom case $(19.3 \mathrm{kcal} / \mathrm{mol})$. This result indicates that both $\mathrm{O}$ and $\mathrm{S}$ atoms of ZDDP molecule can adsorb on the metallic surfaces and the $S$ atom adsorption could more easily occur than the $\mathrm{O}$ atom adsorption, as suggested by their adsorption energies (97.1 vs $19.3 \mathrm{kcal} / \mathrm{mol})$. 

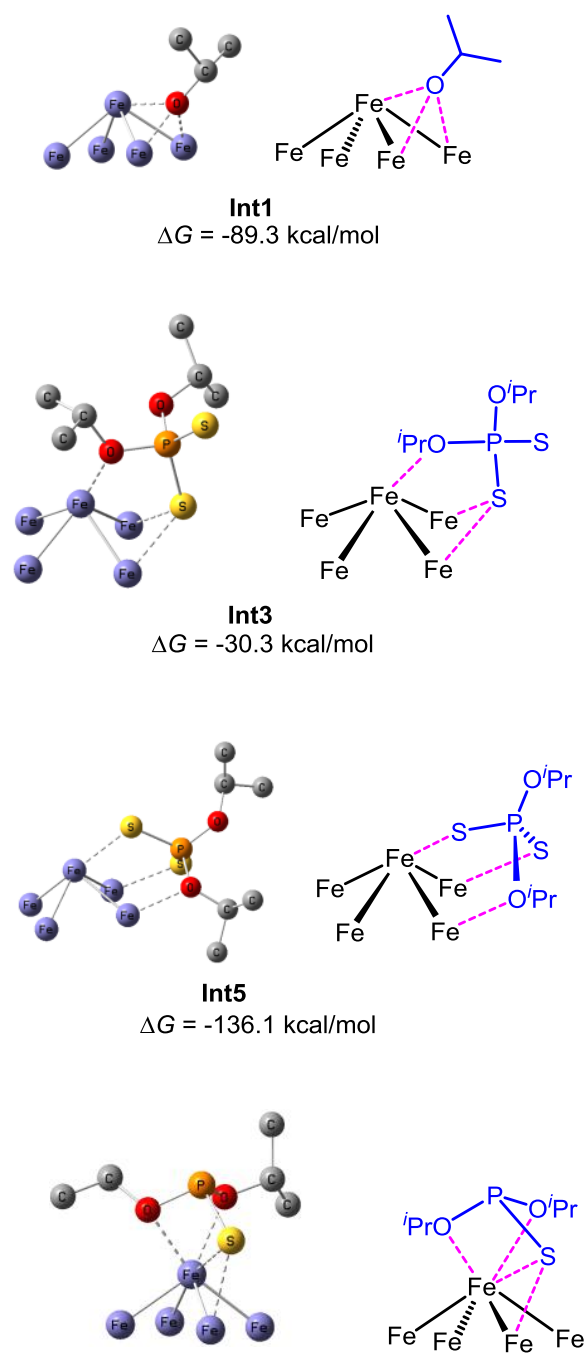

$$
\begin{array}{ll}
\text { Int7 } \\
\Delta G=-85.7 \mathrm{kcal} / \mathrm{mol}
\end{array}
$$

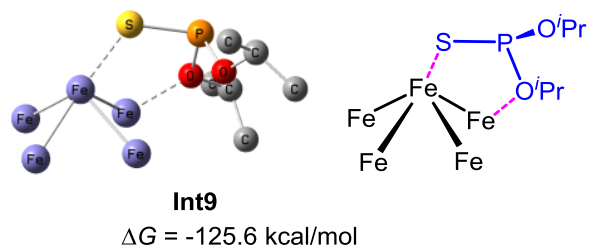

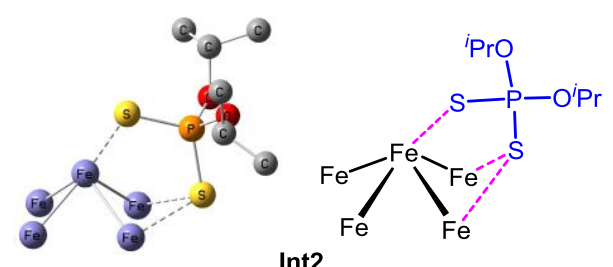

$\Delta G=-105.5 \mathrm{kcal} / \mathrm{mol}$

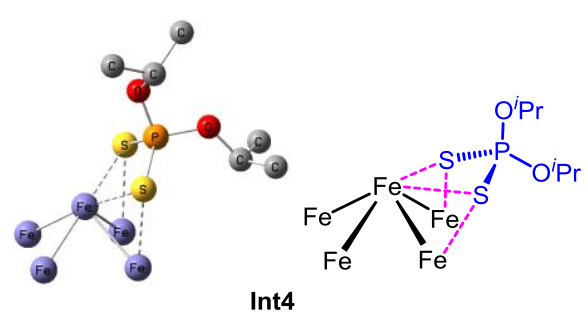

$\Delta G=-32.7 \mathrm{kcal} / \mathrm{mol}$
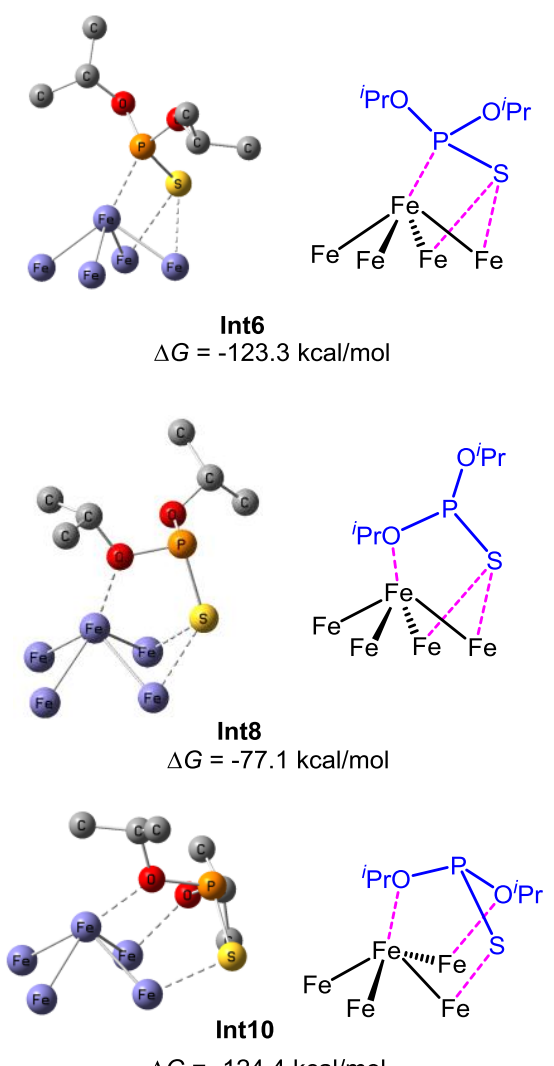

$\Delta G=-124.4 \mathrm{kcal} / \mathrm{mol}$

Figure 5. Structures and their complexation energies $(\mathrm{kcal} / \mathrm{mol})$ of the complexes of $\mathrm{Fe}_{5}$ cluster with radical fragments derived from ZDDP decomposition.

It is generally considered that ZDDPs decompose under normal engine conditions and the decomposition products form "pads" on engine parts to protect the underlying material. ${ }^{53-56}$ As mentioned above, the ZDDP monomers possibly form $\mathrm{RO}^{\circ},(\mathrm{RO})_{2} \mathrm{PS}_{2}{ }^{\circ}$, and $(\mathrm{RO}){ }_{2} \mathrm{PS}^{\circ}$ radicals by the homolysis of $\mathrm{P}-\mathrm{O}, \mathrm{Zn}-\mathrm{S}$, and $\mathrm{P}-\mathrm{S}$ bonds, respectively. To get better understanding of the complexation between organic radical fragments and iron surface, the 
isopropyl-substituted species were studied for the complexation with $\mathrm{Fe}_{5}$ cluster. In species ${ }^{\prime} \mathrm{PrO}^{\circ}$ (species A), the $\mathrm{O}$ atom could simultaneously interact with three $\mathrm{Fe}$ atom of $\mathrm{Fe}_{5}$ cluster to form Int1 (Figure 5) and the complexation process is significantly exergonic by $89.3 \mathrm{kcal} / \mathrm{mol}$. As for the species ('PrO) ${ }_{2} \mathrm{PS}_{2}{ }^{\circ}$ (species $\mathrm{B}$ ) and $(\mathrm{RO})_{2} \mathrm{PS}^{\circ}$ (species $\mathrm{C}$ ), they can form several complexes due to more than one active atoms and multiple complexation manners. As illustrated in Figure 5 , the species B and $\mathrm{Fe}_{5}$ cluster could form complexes Int2-Int5 and the complexes Int6-Int10 could be formed between species $\mathrm{C}$ and $\mathrm{Fe}_{5}$ cluster. All these complexation processes are exothermic and the complexes adopt multi-coordinating manners. In the case of species $B$, the most stable complex is Int5, in which the three active atoms $(\mathrm{S}, \mathrm{S}$, and $\mathrm{O})$ interact with three $\mathrm{Fe}$ atoms of $\mathrm{Fe}_{5}$ cluster. In the case of species C, Int6, Int9, and Int10 show a great stability and the formation of these three complexes are exothermic by about $120 \mathrm{kcal} / \mathrm{mol}$. It is noted that, due to the computational limitation, only $\mathrm{Fe}_{5}$ cluster was chosen as a model of iron surface, which was also applied in previous studies. ${ }^{29,52}$ The multicoordination behavior mentioned here can be regarded as that the studied radical fragments prefer to adsorb on multi-site Fe atoms at the first-layer of iron surface, where the sub-surface was not considered. The results shown in Figure 5 could help us to understand the subsequent adsorption behavior of the resulting organic radical fragments on iron surface.

\section{Conclusions}

In this work, the structural features of various ZDDP monomers, the thermal decomposition of ZDDP monomers and their dimers, and the hydrolysis of alkaline tetranuclear zinc molecules with various alkyl and aryl substituents have been investigated by DFT calculations. The following conclusions could be drawn:

(1) The computational results suggest that both alkyl and aryl substituents have very little effect on geometric parameters of their core structures. The important bond lengths of P-S and $\mathrm{Zn}-\mathrm{S}$ bonds are 2.02-2.04 $\AA$ and 2.46-2.48 $\AA$, respectively. However, the alkyl and aryl substituents have significant effect on the thermal decomposition of ZDDP monomers. It has been found that, for full-alkyl substituted ZDDP molecules, the main decomposition manner is the homolysis of $\mathrm{Zn}-\mathrm{S}$ bond, leading to DPP radicals. Whereas, the $\mathrm{P}-\mathrm{O}$ bond homolysis giving alkoxy radicals is favored for aryl substituted ZDDPs considered in this study.

(2) In ZDDP dimers, the homolysis of $\mathrm{Zn}-\mathrm{S}$ bond of the terminal DDP ligands is much easier than that of bridging DDP ligands. The data shows that most decomposition manners of ZDDP dimers are the loss of DDP radicals and aryloxy radicals for alkyl- and aryl-substituted ZDDP molecules, respectively.

(3) The hydrolysis reaction of tetranuclear dialkyldithiophosphate $\mathrm{Zn}$ complexes becomes easier when the length of alkyl chain increases. Full-alkyl substituted molecules are easier to hydrolyze than aryl-contained ones. In all cases, the hydrolysis reaction free energy reduces when the hydrolysis temperature increases.

(4) The active element $O$ and $S$ could easily interact with metal cluster. The calculated adsorption energy indicates that $S$ atom is easier to interact with $\mathrm{Fe}_{5}$ cluster than $\mathrm{O}$ atom. In addition, the current calculations also suggest that the organic radical fragments derived from ZDDP also tend to be adsorbed on metal surface via multi-coordination manner.

\section{Acknowledgments}

This work was partly supported by grants (No. 21429201) from National Science Foundation of China (NSFC). The authors thank the Network and Information Center of Dalian University of Technology for part of computational resources.

Keywords: Zinc dialkyldithiophosphates (ZDDPs), Substituent effect, Thermal decomposition, Hydrolysis reaction, DFT 


\section{References and Notes}

1. C. N. Rowe, J. J. Dickert, ASLE Trans. 1967, 10, 85.

2. J. Sato, M. Shima, T. Sugawara, A. Tahara, Wear 1982, 52, 52.

3. K. U. Ingold, Chem. Rev. 1961, 61, 563.

4. Y. Luo, S. Maeda, K. Ohno, J. Phys. Chem. A 2008, 112, 5720.

5. A. Kassler, E. Pittenauer, N. Doerr, G. Allmaier, Rapid Commun. Mass $S p$ 2014, 28, 63.

6. Z. Tang, Q. Kong, Y. Luo, W. Xue, J. Qu, H. Chen, X. Fu, J. Theor. Comput. Chem. 2014, 13, 14500035.

7. W. J. Bartz, Engine Oils and Automotive Lubrication; Marcel Dekker: New York, 1993.

8. D. Klamman, Ed. Lubricants and Related Products; Weinheim: Deerfield Beach, FL, 1984.

9. H. C. Freuler, U.S. Patent 2364283, 1944.

10. N. J. Mosey, T. K. Woo, J. Phys. Chem. A 2004, 108, 6001.

11. N. J. Mosey, T. K. Woo, J. Phys. Chem. A 2003, 107, 5058.

12. D. R. Armstrong, E. S. Ferrari, K. J. Roberts, D. Adams, Wear 1997, 208, 138.

13. R. J. Bird, G. P. Galvin, Wear 1976, 37, 143.

14. P. A. Willermet, J. M. Pierprzak, D. P. Dailey, R. O. Carter, N. E. Lindsay, L. P. Haack, J. E. De Vries, ASME Trans. 1991, 113, 38.

15. P. A. Willermet, R. O. Carter, E. N. Boulos, Tribol. Int. 1992, 25, 371.

16. N. J. Mosey, T. K. Woo, Tribol. Int. 2006, 39, 979.

17. N. J. Mosey, M. H. Müser, T. K. Woo, Science 2005, 307, 1612.

18. F. M. Bickelhaupt, E. J. Baerends, Rev. Comput. Chem. 2000, 15, 1.

19. R. Car, M. Parrinello, Phys. Rev. Lett. 1985, 55, 2471.
20. M. J. Frisch, et al. Gaussian 09, Revision D.01, Gaussian, Inc., Wallingford CT, 2009.

21. C. Lee, W. Yang, R. G. Parr, Phys. Rev. 1988, B37, 785.

22. D. Becke, J. Chem. Phys. 1993, 98, 5648.

23. W. R. Wadt, P. J. Hay, J. Chem. Phys. 1985, 82, 284.

24. P. J. Hays, W. R. Wadt, J. Chem. Phys. 1985, 82, 299.

25. V. Barone, M. Cossi, J. Phys. Chem. A 1998, 102, 1995.

26. M. Cossi, N. Rega, G. Scalmani, V. Barone, J. Comput. Chem. 2003, 24, 669.

27. Y. Zhao, D. G. Truhlar, Acc. Chem. Res. 2008, 41, 157.

28. Y. Zhao, D. G. Truhlar, Theor. Chem. Acc. 2008, 120, 215.

29. M. Mousavi, H. Safarizadeh, A. Khosravan, Corrosion Science 2012, 65, 249.

30. P. J. Hay, W. R. Wadt, J. Chem. Phys. 1985, 82, 299.

31. N. E. Gallopoulos, Am. Chem. Soc., DiV. Petrol. Chem., Prepr. 1966, 11, 21.

32. S. Jiang, S. Dasgupta, M. Blanco, R. Frazier, E. S. Yamaguchi, Y. Tang, W. A. Goddard III, J. Phys. Chem. 1996, 100, 15760.

33. M. Fuller, L. R. Fernandez, G. R. Massoumi, W. N. Lennard, M. Kasrai, G. M. Bancroft, Tribol. Lett. 2000, 8, 187.

34. M. L. Suominen Fuller, M. Kasrai, G. M. Bancroft, K. Fyfe, K. H. Tan, Tribol. Int. 1998, 31, 627.

35. Z. F. Yin, M. Kasrai, M. Fuller, G. M. Bancroft, K. Fyfe, K. H. Tan, Wear 1997, 202, 172.

36. P. A. Willermet, R. O. Carter III, P. J. Schmitz, W. Zhu, Tribol. Int. 1995, 28, 177.

37. W. A. Glaeser, D. Baer, M. Engelhardt, Wear 1993, 162-164, 132.

38. P. A. Willermet, R. O. Carter III, E. N. Boulos, Tribol. Int. 1992, 25, 371.

39. P. G. Harrison, P. Brown, J. McManus, Inorg. Chim. Acta 1992, 202, 3. 
40. P. G. Harrison, P. Brown, M. J. Hynes, J. M. Kiely, J. McManus, J. Chem. Res., Synop. 1991, 174.

41. P. G. Harrison, A. Sebald, J. Chem. Res., Synop. 1991, 340.

42. S. L. Lawton, G. T. Kokotailo, Inorg. Chem. 1969, 8, 2410.

43. T. Ito, T. Igarashi, H. Hitosi, Acta Crystallogr., Sect. B 1969, B25, 2303.

44. A. V. Ivanov, O. N. Antzutkin, A.-C. Larsson, M. Kritikos, W. Forsling, Inorg. Chim. Acta 2001, 315, 26.

45. D. R. Armstrong, E. S. Ferrari, K. J. Roberts, D. Adams, Wear 1997, 208, 138.

46. A. V. Ivanov, O. N. Antzutkin, A. Larsson, M. Kritikos, W. Forsling, Inorg. Chim. Acta 2001, 315, 26.

47. Ph. G. Harrison, M. J. Begley, T. Kikabhai, F. Killer, J. Chem. Soc., Dalton Trans. 1986, 925.

48. J. Burn, G. W. Smith, Chem. Commun. (London) 1965, 394.

49. A.-C. Larsson, A. V. Ivanov, W. Forsling, O. N. Antzutkin, A. E. Abraham, A. C. de Dios, J. Am. Chem. Soc. 2005, 127, 2218.

50. M. A. Malik, P. O'Brien, M. Motevalli, I. Abrahams, Polyhedron 2006, 25, 241.

51. C. G. Lugmair, T. D. Tilley, A. L. Rheingold, Chem. Mater. 1997, 9, 339.

52. M. R. Arshadi, M. Lashgari, Gh. A. Parsafar, Mater. Chem. Phys. 2004, 86, 311.

53. K. Varlot, M. Kasrai, J. M. Martin, B. Vacher, G. M. Bancroft, E. S. Yamaguchi, P. R. Ryason, Tribol. Lett. 2000, 8, 9.

54. A. G. Papay, Lubr. Sci. 1998, 10, 209.

55. P. A. Willermet, J. M. Pieprzak, D. P. Dailey, R. O. Carter III, N. E. Lindsay, L. P. Haack, J. E. DeVries, ASLE Trans. 1991, 113, 38.

56. R. J. Bird, G. P. Galvin, Wear 1976, 37, 143. 
Computational Studies on the Effects of Substituents on the Structure and Property of Zinc Dialkyldithiophosphates

Weiguo Xue, Xisheng Fu, Zhongping Tang, Gen Luo, Wenjie An, Tao Li, Yi Luo, Xuguang Zhou, and Yi Luo, ${ }^{*}$

The substituent effect on the structure and property of zinc dialkyldithiophosphates (ZDDPs) was investigated by DFT calculations. The results indicate that the substituents have very little effect on their structures, but have significant effect on the thermal decomposition of alkyl-and aryl-substituted ZDDPs and their dimers. The hydrolysis reaction free energies of tetranuclear dialkyldithiophosphate zinc complexes are affected by the substituents and the hydrolysis temperature.

DFT Study<smiles>O[Se][Te]12S[Pb]O[PH]([18O])(S1)S2</smiles>

The substituent effect on the structure and property of ZDDPs 